\title{
Influence of ascorbic acid, sulfur dioxide and glutathione on oxidation product formation in wine-like systems
}

\author{
Pascal Wegmann-Herr ${ }^{1, a}$, Miriam Berner ${ }^{2}$, Christian Dickescheid ${ }^{3}$, Christian v. Wallbrunn ${ }^{3}$, Patrick Nickolaus ${ }^{1}$, \\ and Dominik Durner ${ }^{1}$ \\ ${ }^{1}$ Departement of Viticulture and Enology, DLR Rheinpfalz, Breitenweg 71, 67435 Neustadt/W, Germany \\ ${ }^{2}$ Technical University Munich, General Food Technology Freising, Germany \\ ${ }^{3}$ Hochschule Geisenheim University, Germany
}

\begin{abstract}
The impact of the addition of ascorbic acid, sulfur dioxide and glutathione on oxidation product formation under accelerated oxidative conditions was evaluated in model wines. The effects of these antioxidants have been compared in aqueous ethanol solutions containing (+)-catechin and metal ions at $\mathrm{pH} 3.2$ by monitoring $\mathrm{O} 2$ consumption, color evolution by CIELab, as well as (+)-catechin and glutathione decrease by LC-DAD/FD. The analysis of oxidation products formation was focused on the determination of yellowish colored xanthylium compounds by LC-ESI-ToFMS and acetaldehyde by HS-GC-FID. The results could show, that under some conditions glutathione could not inhibit carboxymethine-briged (+)-catechine dimer formation and subsequent xanthylium cation pigment generation, compared to ascorbic acid or sulfur dioxide addition providing a good protection against oxidative color changes. In systems containing 0.08 to $0.32 \mathrm{mmol} / \mathrm{L}$ glutathion without any further addition of $\mathrm{SO}_{2}$ or ascorbic acid, increasing acetaldehyde concentrations could be observed. These results demonstrate clearly the need for further research to highlight the reactions of glutathione.
\end{abstract}

\section{Introduction}

During the whole vinification process wine compounds take part in chemical reactions that affect the sensory properties. The mayor activator for these reactions is oxygen, which is especially damaging white wines. Chemical oxidation, catalyzed by copper and iron, can arise through several pathways which are mostly related to phenols, to form reactive oxygen species such as hydrogen peroxide $\left(\mathrm{H}_{2} \mathrm{O}_{2}\right)$ [1]. So-called antioxidants such as ascorbic acid $(\mathrm{AA})$, sulfur dioxide $\left(\mathrm{SO}_{2}\right)$, and glutathione $(\mathrm{GSH})$ are used to prevent oxidation. Whilst sulfur dioxide is the most common preservative used in winemaking especially glutathione became of major interest the last years [2]. The main anti-oxidative activity of $\mathrm{SO}_{2}$ is the reaction of the bisulfite ion with $\mathrm{H}_{2} \mathrm{O}_{2}$ to form sulfuric acid, changing the oxidation state of sulfur from +IV to +VI, AA can directly react with molecular oxygen to generate dehydroascorbic acid and $\mathrm{H}_{2} \mathrm{O}_{2}$. The reaction of GSH seems to be either via the reaction with active oxygen species to form the glutathione disulfide (GSSG) or to form addition products with carbonyl or $o$-quinone compounds [3,4]. Negative oxidative evolution of white wines can result in the loss of pleasant aroma compounds, increase in acetaldehyde concentration or oxidative color evolution. Oxidative color evolution might be attributed to tartaric acid oxidation resulting in glyoxylic acid formation and subsequently carboxymethine-bridged (+)-catechin generation. Yellow xanthylium cation pigments are generated after

${ }^{a}$ Corresponding author: pascal .wegmann-herr@dlr.rlp.de dehydration of the dimer and another oxidation step [5,6]. Acetaldehyde is formed by oxidation of ethanol involving hydrogen peroxide resulting from the oxidation of vicinal diphenols [7]. This reaction requires metal ions such as $\mathrm{Fe}^{2+}$ and is known as Fenton reaction [8].

\section{Materials and methods}

A wine-like solution was prepared with aqueous ethanol $(12 \% \mathrm{v} / \mathrm{v})$ containing $0.033 \mathrm{M}$ tartaric acid, $0.022 \mathrm{mM}$ $\mathrm{Fe}(\mathrm{II}), \mathrm{Fe}(\mathrm{III})$ and $0.019 \mathrm{mM} \mathrm{Cu}$ (II) per liter(*). The $\mathrm{pH}$ of the solution was 3.2. Depending on the treatment, 0 to $0.68 \mathrm{mM}(+)$-catechin, 0 to $0.32 \mathrm{mM} \mathrm{GSH}$; 0 to $0.8 \mathrm{mM}$ AA, 0 to $0.27 \mathrm{mM}$ caffeic acid and, 0 to $0.78 \mathrm{mM} \mathrm{K}_{2} \mathrm{SO}_{5}$ per liter were added. After saturation with $8.4 \mathrm{ppm} \mathrm{O}_{2}$, samples $(100 \mathrm{~mL})$ were placed in Schott Duran reagent bottles without headspace. All samples were prepared in triplicate and stored in darkness at $50^{\circ} \mathrm{C}$ for 7 or 10 days. (+)-Catechin and GSH were detected using a LC-FD/ DAD system (Jasco). Methylmethin- and carboxymethinbridged (+)-catechin dimers $(607 \mathrm{~m} / \mathrm{z}$ and $637 \mathrm{~m} / \mathrm{z}$, respectively), procyanidins $(577 \mathrm{~m} / \mathrm{z}$ for type A and $579 \mathrm{~m} / \mathrm{z}$ for type B) as well as xanthylium cation pigments $617 \mathrm{~m} / \mathrm{z}$ were all identified in positive ion mode on a Agilent 1260 UPLC system equipped with a Agilent 6530 Accurate Mass ESI-QToFMS and G4212B DAD detection system. The column was a Phenomenex Kinetex C18 $(150 \times 2.1 \mathrm{~mm}$ i.d.) with $2.6 \mu \mathrm{m}$ particle diameter. The same system with a Phenomenex Kinetex HILIC $(50 \times 2.1 \mathrm{~mm}$ i.d. $)$ with $2.6 \mu \mathrm{m}$ particle diameter in negative ion mode was used to 
identify tartaric acid $(149 \mathrm{~m} / \mathrm{z})$ and glyoxylic acid $(73 \mathrm{~m} / \mathrm{z})$. Acetaldehyde was detected by HS-GS-FID. The chromatographic separation was performed in a GC 8000 Top, Carlo Erba Instruments (Thermo Fisher), equipped with a CP-Sil 19 column $(10 \mathrm{~m} \times 0.53 \mathrm{~mm}$ i.d. $\times 2.1 \mu \mathrm{m}$ film thickness; Agilent) combined with a DB1 column $(30 \mathrm{~m} \times 0.53 \mathrm{~mm}$ i.d. $\times 3 \mu \mathrm{m}$ film thickness; Agilent). CIELAB chromatic coordinates were determined and calculated using a Varian Cary 100 spectrophotometer and the Color Software (version 3.20).

\section{Results and discussion}

The wine-like solution was prepared like indicated in materials and methods ${ }^{(*)}$. Depending on the experiment this solution was supplemented with (+)-catechin, GSH, AA, caffeic acid and $\mathrm{K}_{2} \mathrm{SO}_{5}$ in various concentrations.

\subsection{Influence of $\mathrm{SO}_{2}, \mathrm{AA}$ and $\mathrm{GSH}$ on xanthylium cation formation}

To the model system supplemented with $0.17 \mathrm{mM} / \mathrm{L}$ (+)-catechin, either $0.16 \mathrm{mM} / \mathrm{L} \mathrm{GSH}, 0.28 \mathrm{mM} / \mathrm{L} \mathrm{AA}$ or $0.4 \mathrm{mM} / \mathrm{L} \mathrm{K}_{2} \mathrm{SO}_{5}$ were added. These systems have been used to compare the impact of antioxidants on oxidative color evolution due to yellowish xanthylium cation formation.

The results showed that both $\mathrm{SO}_{2}$ and AA could reduce oxidative color changes and xanthylium cation formation with $\mathrm{SO}_{2}$ providing the best protection. The addition of GSH led to a significant increase in xanthylium cation formation (Fig. 1) and a green-yellowish color (Fig. 2) and could not inhibit carboxymethine-bridged (+)-catechin dimer formation.

Only small amounts of methylmethin- and carboxymethin- bridged (+)-catechin dimers could be detected in samples with $\mathrm{SO}_{2}$ addition. The antioxidative effect of $\mathrm{SO}_{2}$ is based on the direct reaction with $\mathrm{H}_{2} \mathrm{O}_{2}$ as high amounts of $\mathrm{SO}_{4}{ }^{2-}$ could be detected. Furthermore, the formation of larger amounts of glyoxylic acid showed that $\mathrm{SO}_{2}$ was not able to completely prevent the first oxidation step of tartaric acid. However its ability to react with oxidation products inhibits the further reactions involved in xanthylium cation formation probably generating a bisulfite addition product with glyoxylic acid

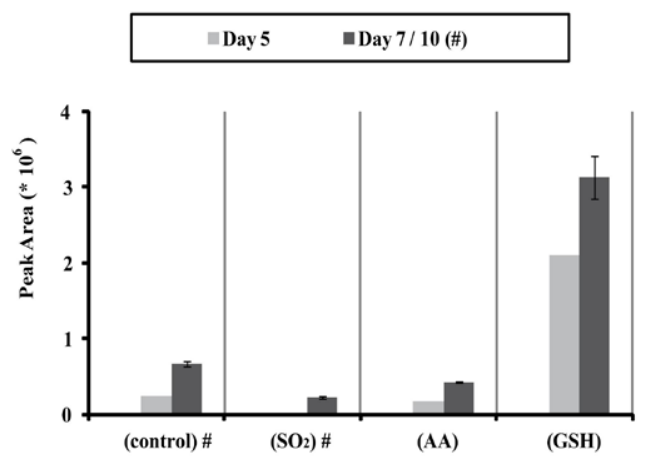

Figure 1. Impact of antioxidants on xanthylium cation production.

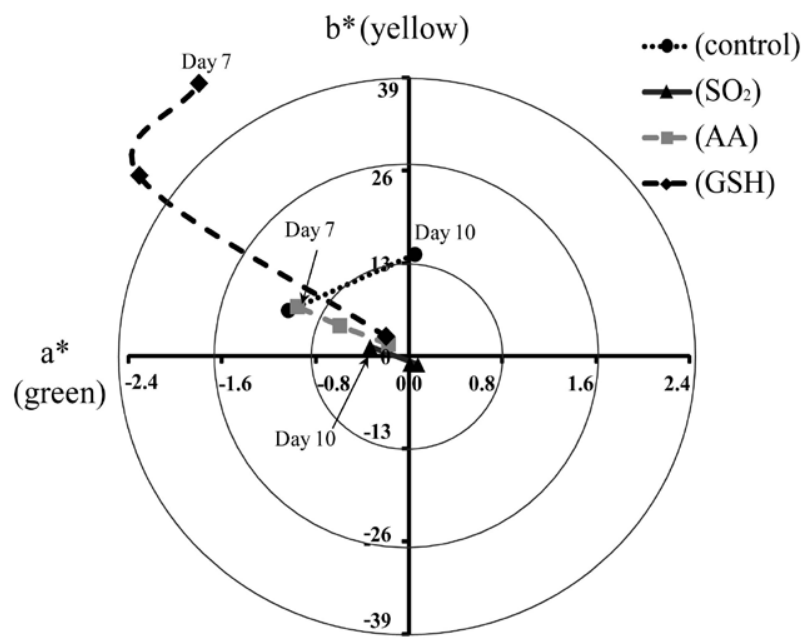

Figure 2. Impact of antioxidants on chromatic $a^{*}$ and $b^{*}$ space.

[4]. Regarding the effect of AA addition, there seems to be a competitive effect with the xanthylium cation formation. (+)-MHF-catechin as indicator of dehydroascorbic acid degradation as well as glyoxylic acid were detected. The $\mathrm{H}_{2} \mathrm{O}_{2}$ resulting from (+)-catechin or AA oxidation is able to oxidize some tartaric acid with the subsequent formation of xanthylium cations. However AA might reduce $o$-quinone compounds. The AA addition treatment showed the fastest $\mathrm{O}_{2}$ consumption. As a result no active $\mathrm{O}_{2}$ species are left to perform the final oxidation step of the xanthylium cation precursors. In comparison to the other investigated antioxidants GSH is not able to impede the development of oxidative color. Contrary to what was expected, GSH addition triggered xanthylium cation formation under the conditions tested.

\subsection{Impact of glutathion on the formation of acetaldehyde}

To the stock solution ${ }^{*}$ concentrations ranging from $0 \mathrm{mM} / \mathrm{L}(0 \mathrm{mg} / \mathrm{L})$ to $0.32 \mathrm{mM} / \mathrm{L}(100 \mathrm{mg} / \mathrm{L}) \mathrm{GSH}$ and $0 \mathrm{mM} / \mathrm{L}(0 \mathrm{mg} / \mathrm{L})$ to $0.68 \mathrm{mM} / \mathrm{L}(100 \mathrm{mg} / \mathrm{L})(+)$-catechin have been added, thus giving $\mathrm{mM}$ ratios $\mathrm{GSH} /(+)$-catechin from 0 to $1: 1 ; 1: 4 ; 2: 1 ; 5: 1$ and 10:1. No further supplementation occurred to avoid supplement effects on acetaldehyde formation. Like it is shown in Fig. 3 there is a linear correlation between the amount of GSH added and the concentration of acetaldehyde generated. The statistical model indicates increasing acetaldehyde concentrations with increasing GSH additions, showing a relatively high coefficient of determination $\left(R^{2}: 0.9133\right)$.

Even small amounts of GHS $(0.08 \mathrm{mM} / \mathrm{L}$ or $25 \mathrm{mg} / \mathrm{L})$ lead to acetaldehyde concentration ranging from $7 \mathrm{mg} / \mathrm{L}$ to $9.2 \mathrm{mg} / \mathrm{L}$. High concentrations of acetaldehyde (from $17.9 \mathrm{mg} / \mathrm{L}$ to $18.7 \mathrm{mg} / \mathrm{L}$ ) were detected at $\mathrm{GSH}$ additions of $0.32 \mathrm{mM} / \mathrm{L}$ or $100 \mathrm{mg} / \mathrm{L}$. Assuming a total reaction of acetaldehyde with $\mathrm{H}_{2} \mathrm{SO}_{3}$ under winemaking conditions these concentrations would correspond to $10 \mathrm{mg} / \mathrm{L}$ and $27 \mathrm{mg} / \mathrm{L}$ bound $\mathrm{SO}_{2}$. Never the less additional data are required for the validation of the model, especially in lower concentrations as $0.32 \mathrm{mM} / \mathrm{L}$ GSH are very high. In this study the model system has been kept quite simple 


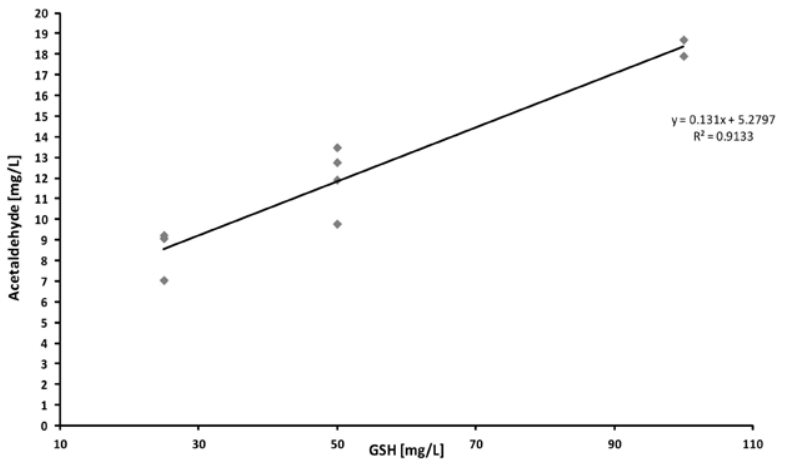

Figure 3. Formation of acetaldehyde under oxidative conditions in presence of glutathion.

to highlight single reaction mechanisms but wine is a far more complex system and possible interactions in presence of various compounds affecting the redox-system must be considered. Even if the reaction mechanism of GSH remains unclear we have to state that the acetaldehyde formation due to GSH addition is not coupled to reactions involving (+)-catechin. The reaction does therefore not require reactive oxygen species resulting from the oxidation of vicinal diphenols. The direct activation of $\mathrm{O}_{2}$ to reactive oxygen species by GSH might be possible and should be explained in further studies. To our knowledge it is the first time the involvement of GSH in acetaldehyde formation in model systems is reported.

\subsection{Oxidative reactions and interaction with glutathion}

As already mentioned wine is a far more complex system than most of the model system used to explain reactions under defined conditions. The PCA in Fig. 4 shows the influence of different more or less complex model systems on determined oxidation parameters. Basically the same model system as described in section $2^{(*)}$ but then supplemented with different additives. Samples 5, 6 and 7 contained the combination of $0.16 \mathrm{mM} / \mathrm{L} \mathrm{GSH}+0.17 \mathrm{mM} / \mathrm{L}$ (+)-catechin; $0.08 \mathrm{mM} / \mathrm{L} \mathrm{GSH}+0.68 \mathrm{mM} / \mathrm{L}(+)$-catechin; $0.32 \mathrm{mM} / \mathrm{L} \mathrm{GSH}+0.17 \mathrm{mM} / \mathrm{L}(+)$-catechin respectively. Sample 12 contained $0.16 \mathrm{mM}$ GSH $+0.17 \mathrm{mM}(+)$-catechin and $0.8 \mathrm{mM}$ AA per liter. Sample 11 was like sample 12 but with $0.78 \mathrm{mM} \mathrm{SO}_{2}$ per liter. Samples 8, 9 and 10 contained all $0.78 \mathrm{mM} \mathrm{SO}_{2}$ per liter and different GSH/ (+)-catechin ratios. Sample 8 with $0.16 \mathrm{mM} \mathrm{GSH}$ and $0.17 \mathrm{mM}(+)$-catechin, sample 9 with $0.08 \mathrm{mM} \mathrm{GSH}$ and $0.17 \mathrm{mM}(+)$-catechin and sample 10 with $0.16 \mathrm{mM} \mathrm{GSH}$ and $0.08 \mathrm{mM}(+)$-catechin per liter. Samples 14 and 15 contained caffeic acid $(0.27 \mathrm{mM} / \mathrm{L})$ and $0.016 \mathrm{mM} / \mathrm{L}$ (+)-catechin additionally with 14 having $0.08 \mathrm{mM} / \mathrm{L} \mathrm{GSH}$ and 15 having $0.16 \mathrm{mM} / \mathrm{L}$ GSH.

As shown in Fig. 4 approximately four clusters can be formed using the PCA. The group GSH + catechine + ascorbic acid is explained by strong GSH depletion, acetaldehyde formation and the formation of cat-mm-cat dimmers. The group GSH + catechine is in good correlation with xanthylium cation formation together with its precursor cat-cm-cat. In the same time there is more oxidation of GSH resulting in the disulfide GSSG and color change $(\Delta E)$. The two groups on the negative part of $\mathrm{PC} 1$ are in negative correlation with oxidation product formation. Both, the addition of $\mathrm{SO}_{2}$ and caffeic acid seem to inhibit negative effects and are more explained by $\mathrm{O}_{2}$ consumption rather than oxidation product formation. The application of $\mathrm{SO}_{2}$ helps to capture reactive oxygen itself reacting to sulfuric acid. The addition of caffeic acid might provide positive effects by reacting with GSH to form GRP1 even under chemical oxidation conditions.
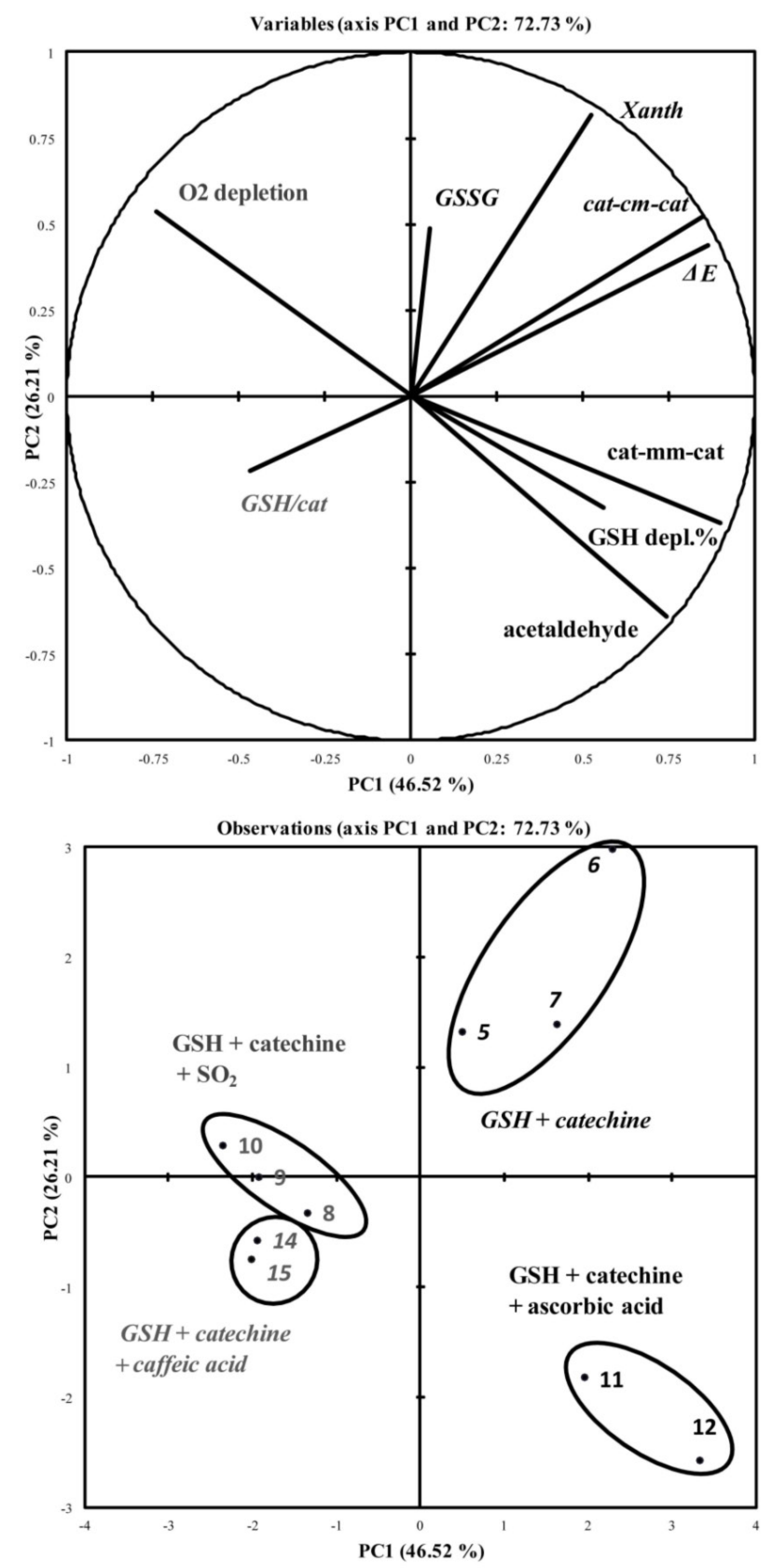

Figure 4. Principal components analysis of different model wine systems. Projection of oxidation parameters determined after 12 days of accelerated oxidation on PC1 and PC2. The loadings of the oxidation parameters are calculated with the average of three repetitions and are shown in the upper part. The scores of the experiments are shown in the lower part. Circles do not represent any confidence interval. 


\section{Conclusion}

In comparison to the other investigated antioxidants GSH is not able to impede the development of oxidative color. Contrary to what was expected, GSH addition triggered xanthylium cation formation under the conditions tested. At a molar ratio of GSH to (+)-catechin of almost $1: 1$, one assumption is the already reported polymeric pigment formation due to GSH depletion [3]. This depletion may be ascribed to GSSG or $o$-quinone addition products formation. The applied $\mathrm{O}_{2}$ generates $o$-quinone with subsequent $\mathrm{H}_{2} \mathrm{O}_{2}$ formation. $O$-quinones might react with GSH whereas the remaining $\mathrm{H}_{2} \mathrm{O}_{2}$ catalyzes tartaric acid oxidation and subsequent xanthylium cation formation. Another pathway might be the formation of glutathiyl radicals acting as prooxidants as is the case in lipid peroxidation [9]. The radicals might also be responsible for increasing acetaldehyde concentrations. These results demonstrate clearly the need for further research to highlight the reactions of Glutathion in wine.

\section{References}

[1] J.C. Danilewicz, Am.J.Enol.Vitic. 54 (2) (2003) 73-85

[2] E.C. Kritzinger, F.F. Bauer and Toit, J. Agric. Food Chem. 61 (2013) 269-277

[3] F. Sonni, A.C. Clark, P.D. Prenzler, C. Riponi and G. R. Scollary, J.Agric.Food Chem. 59 (2011) 3940-3949.

[4] F. Sonni, A.C. Clark, P.D. Prenzler, C. Riponi and G. R. Scollary, J.Agric.Food Chem. 59 (2011) 7410-7418.

[5] H. Fulcrand, V. Cheynier, J. Oszmianski and M. Moutonet, Phytochemistry. 46 (1997) 223-227.

[6] N. Es-Safi, C. Le Guernevé, H. Fulcrand, V. Cheynier and M. Moutonet, J.Agric.Food Chem. 47 (1999) 5211-5217

[7] H.L. Wildenradt and V.L. Singleton, Am.J.Enol. Vitic. 25 (1974) 119-126

[8] A.L. Waterhouse and V.F. Laurie, Am.J.Enol.Vitic. 57 (2006) 306-313

[9] C. Schöneich and K.D. Asmus, Radiat Environ Biophys. 29 (1990) 263-271 